Engineering Physics and Mathematics Division

\title{
Adapting Sensory Data for Multiple Robots Performing Spill Cleanup
}

\author{
Kai Storjohann \\ Eric Saltzen
}

DATE PUBLISHED - September 1990

Prepared for

Office of Basic Energy Sciences, B\&R KC 04. 030

Prepared by the

OAK RIDGE NATIONAL LABORATORY

Oak Ridge, Tennessee 37831 operated by

MARTIN MARIETTA ENERGY SYSTEMS, INC. for the

U.S. DEPARTMENT OF ENERGY under contract DE-AC05-84OR21400

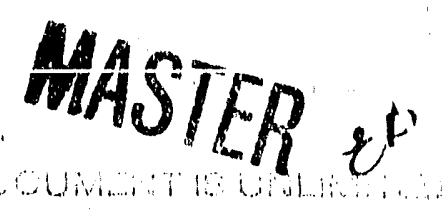




\section{CONTENTS}

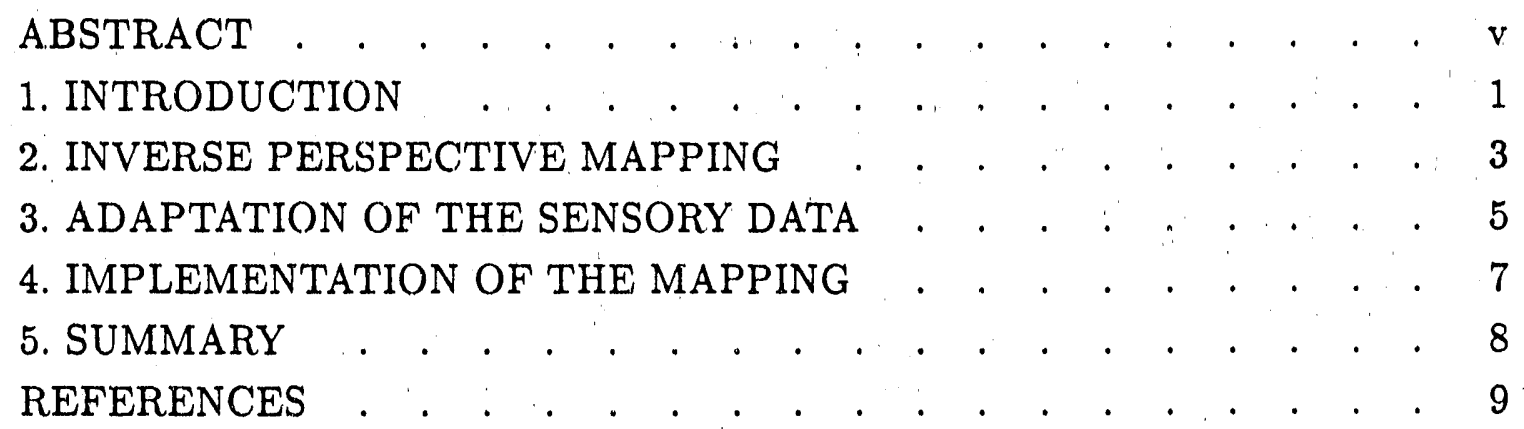




\begin{abstract}
This paper describes a possible method of converting a single performing robot algorithm into a multiple performing robot algorithm without the need to modify previously written codes. The algorithm to be converted involves spill detection and clean up by the HERMIES-III mobile robot. In order to achicve the goal of multiple performing robots with this algorithm, two steps are taken. First, the task is formally divided into two sub-tasks, spill detection and spill clean-up, the former of which is allocated to the added performing robot, HERMIES-IIB. Second, a inverse perspective mapping, is applied to the data acquired by the new performing robot (HERMIES-IIB), allowing the data to be processed by the previously written algorithm without re-writing the code.
\end{abstract}




\section{INTRODUCTION}

The U.S. Department of Energy, Office of Nuclear Energy, sponsors a joint university/ORNL research project pursuing the development of advanced robotic systems that are capable of operation in hazardous environments [1]. In 1988, the mobile robot HERMIES-IIB planned and followed a path in a partially known environment. The target of these maneuvers, a mock control panel, was found and inspected. HERMIES-III is the more sophisticated successor of HERMIES-IIB and is equipped with a seven degrees of freedom manipulator. In 1989, it navigated autonomously through an obstacle ridden environment and detected, located, and cleaned up a simulated spill using a vacuum cleaner mounted on the tip of its manipulator. The spill cleaning task for HERMIES-III consisted of two main subtasks accomplished sequentially. In addition to navigation in an obstacle ridden environment, each sub-task required a specific sensory and effectual capability; a vision system was required for the spill detection and a manipulator was required for the spill clean up.

When such a task consists of two or more sub-tasks that can be performed concurrently or consecutively, and the sub-tasks require differing system performances, it can be appropriate to distribute the sub-tasks to multiple robots to minimize either the "task time" or the costs for the "job". For the spill cleaning task, this means that the spill detection could be accomplished by HERMIES-IIB and the spill clean up by HERMIES-III. HERMIES-IIB would seek out the spill and transmit the spill location, size and shape to HERMIES-III, whereupon the larger robot could move directly to the spill and remove it.

Transferring the proven spill detection system of HERMIES-III onto HERMIESIIB could be part of the strategy to achieve the goal of multiple performing robots. However, this is complicated by the following geometric constraint. On HERMIESIII, a camera attached to the tip of the manipulator images the floor and an image processing software module [2] detects and maps spills. This eye-in-hand camera is oriented so that the image plane of the camera is parallel to the floor. This camera geometry provides a simple relation between image coordinates and floor coordinates for the software module. But due to the mechanical design of the robot, a camera mounted on HERMIES-IIB cannot assume the pose of the HERMIES-III camera (Fig. 1). In addition to this constraint, it would be expedient to use the cameras and lenses already mounted on HERMIES-IIB, which are different from those on HERMIES-III. Doing so would further alter the relation between image and floor coordinates that was established for the HERMIES-III algorithm.

For the above reasons, the HERMIES-III image processing software cannot be used on HERMIES-IIB without adaptations. An elegant method to avoid direct modification of the image processing software is to map the HERMIES-IIB camera images to the perspective of the HER MílES-III camera, by applying a coordinate transformation termed inverse perspective mapping [3]. 


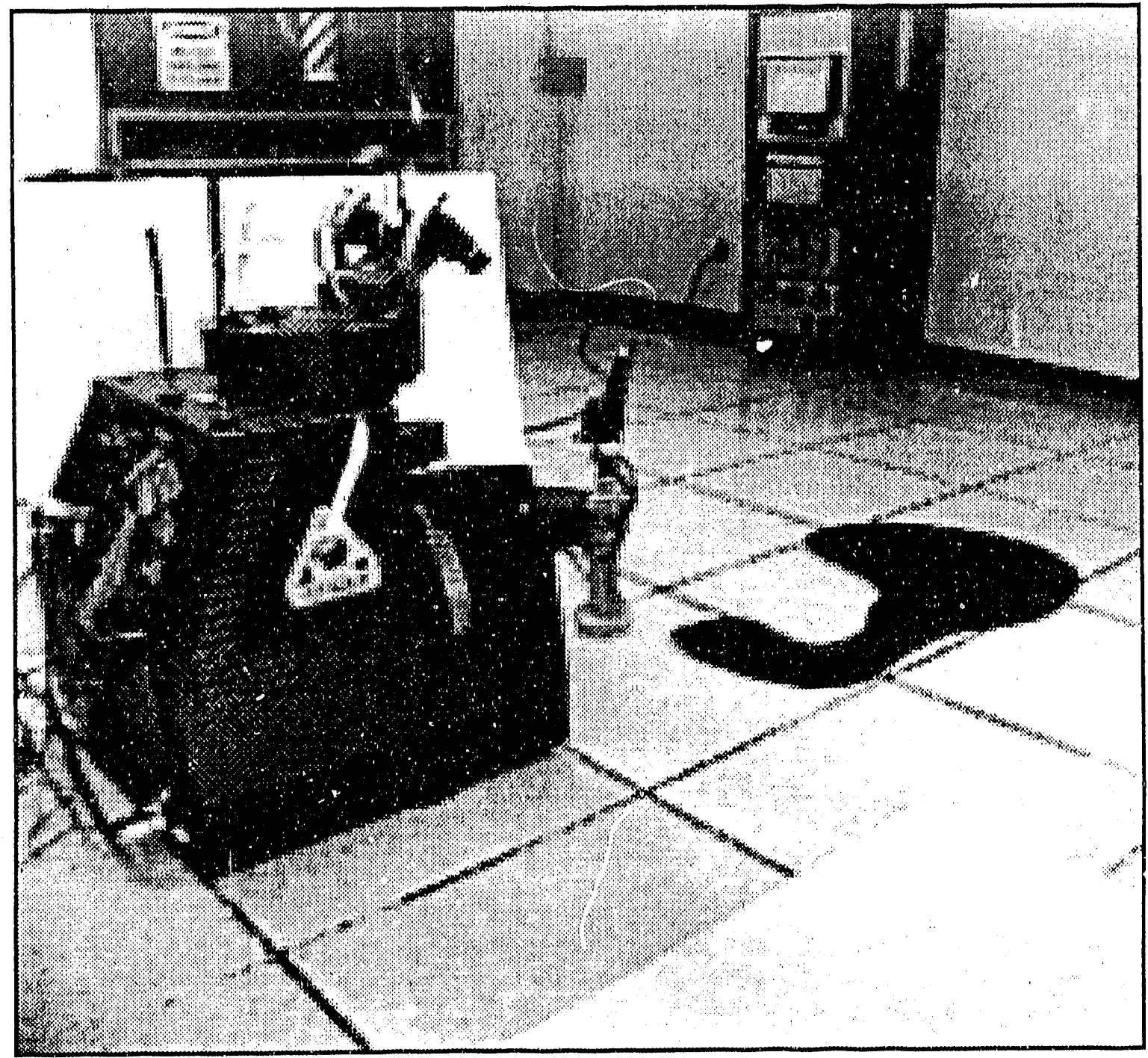

Fig. 1. HERMIES-IIB at simulated spill site with cameras directed at the floor (cameras located on "head" of robot). 


\section{INVERSE PERSPECTIVE MAPPING}

Inverse perspective mapping projects the image of a camera onto a plane different from the original image plane while retaining the center of projection. Fig. 2 shows an object point $P$ in space being viewed by a camera with lens nodal point $\mathrm{O}$ and image plane $\mathrm{E}$.

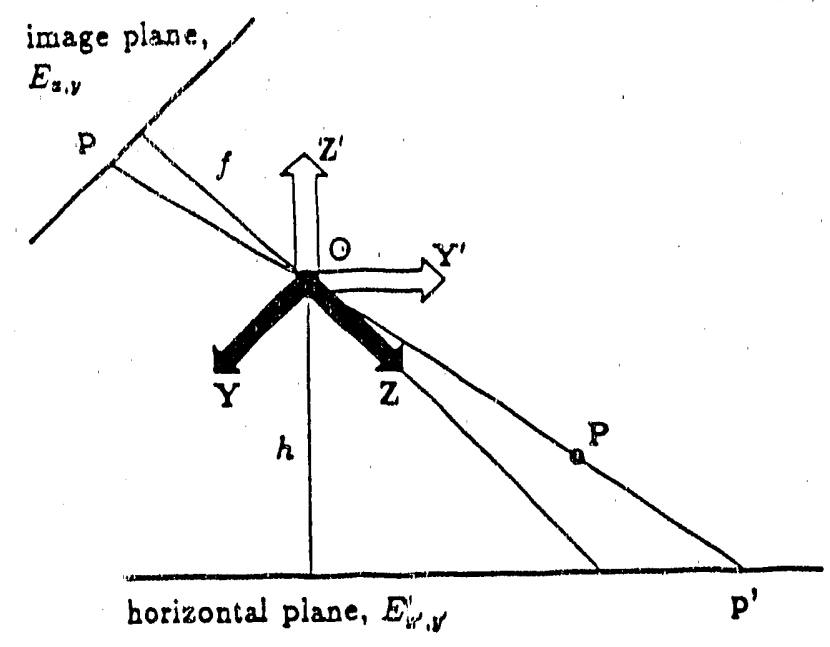

Fig. 2, Coordinate sytems for the inverse perspective mapping.

The image point $\mathrm{p}$ of $\mathrm{P}$ is determined by the process of central projection, i.e. it is the point where the ray from the object point to the nodal point intersects the image plane. Then the inverse perspective mapping of $p$ onto a plane $E$ ' is given by the point of intersection of the same ray with $E$ '. The inverse perspective mapping $\mathrm{Q}: \mathrm{E} \rightarrow \mathrm{E}^{\prime}$ maps point $\mathrm{p}(\mathrm{x}, \mathrm{y})$ in the image plane $\mathrm{E}$ onto a point $\mathrm{p}^{\prime}\left(\mathrm{x}^{\prime}, \mathrm{y}^{\prime}\right)$ in a plane $E^{\prime}$ slanterl by an angle $\varphi$ with respect to the optical axis:

$$
\begin{aligned}
\mathcal{Q}: \mathrm{R}^{2} & \mapsto \mathrm{R}^{2} \\
\left(\begin{array}{l}
x^{\prime} \\
y^{\prime}
\end{array}\right) & =\frac{h}{-v^{\prime} \cos \varphi+f \sin \varphi} \cdot\left(\begin{array}{c}
u^{\prime} \\
v^{\prime} / \sin \varphi
\end{array}\right) .
\end{aligned}
$$

(Note: Without loss of generality for the definition above, the $\mathrm{X}$ and $\mathrm{X}$ 'axis are chosen to coincide). Inverse perspective mappings as defined here can also be viewed 
as the class of image transformations that could be achieved by changing the focal length or camera target orientation relative to the optical axis. It is this feature of inverse perspective mapping that is exploited to change the orientation and focal length of HERMIES-IIB's camera to match that of HERMIES-III's camera.

In terms of projective geometry, inverse perspective mapping is a projective collineation [4]. Its application to images has been reported by Gonzales and Wintz [5], and its functional implications on the computation of optical flow and stereo by Mallot, et al [3]. 


\section{ADAPTATION OF THE SENSORY DATA}

The implementation of inverse perspective mapping is rather simple. After measuring $h$ - the height of the cameras nodal point above the floor, and $\varphi$ the inclination angle of the cameras optical axis with the floor, all parameters of Equation 1 are known. If a more accurate estimation of the orientation parameters is required, any calibration method for standard cameras can be utilized (e.g. [6]). Fig. 3 shows a view of the floor from a HERMIES-IIB camera.

Fig. 3. View of the simulated spill from a HERMIESIIB camera.

The perspective distortion of the imaged floor is due to the non- orthogonal view of the camera. This image is then mapped into a new image frame by applying Equation 1. As a result of the inverse perspective mapping, the distortion of the floor is compensated for and the mapped image (Fig. 4) can be passed to any succeeding image processing module, providing an orthogonal view of the floor. 


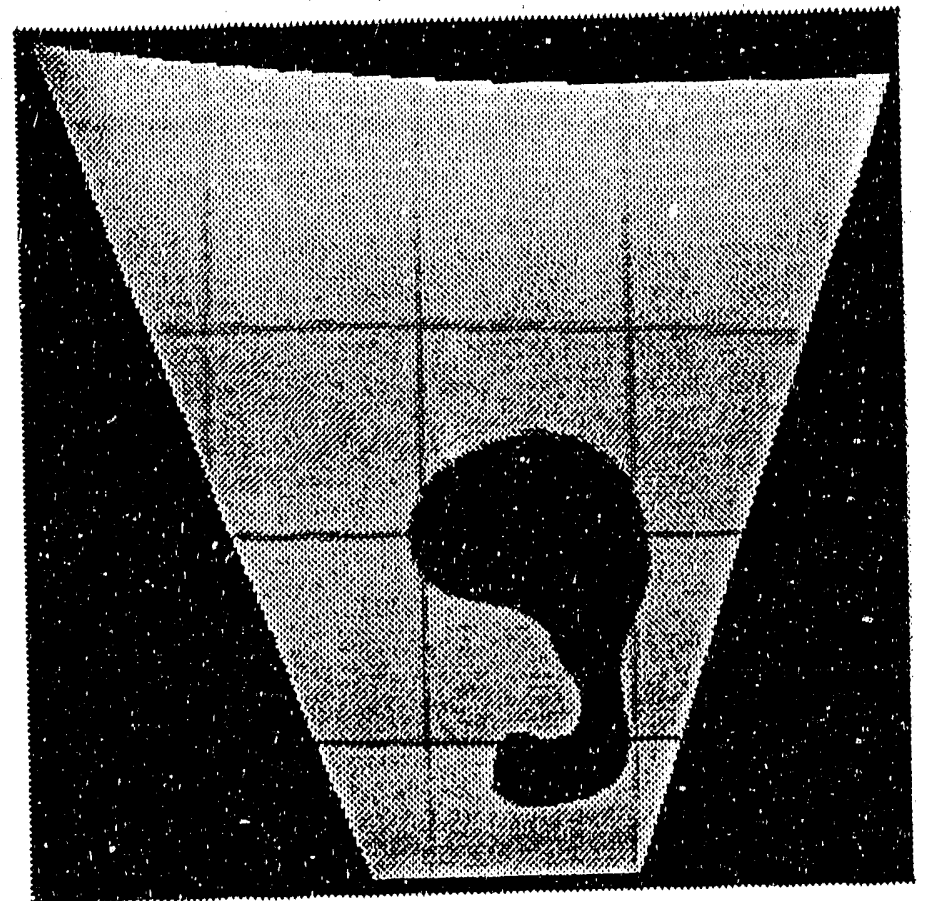

Fig. 4. HERMIES-IIB, view of the spill after inverse parspective mapping has been applied to the image. 


\section{IMPLEMENTATION OF THE MAPPING}

In order to perform the mapping function, the destination of each pixel in the original image must be calculated. This may take quite some time, as equation 1 must be solved for every pixel in the image. For a $256 \times 256$ image it took approxirnately 3 minutes to perform the mapping on a $68020 \mathrm{VME}$ bus system. However, the performance can be greatly improved by first computing a look-up table. We can consider the orientation of the camera to be stationary, because neither its height nor inclination change, even if the robot is moving (on a plane). Therefore, if we compute a lookup table that contains the calculated destination for each pixel in the original image, we can quickly map any images with a single pass through the lookup table. For a $256 \times 256$ image it took approximately 1.75 seconds to perform the mapping on a $68020 \mathrm{VME}$ bus system using a previously computed look-up table. Another advantage of the lookup table scheme is that it is readily adaptable to a parallel computer architecture, such as a hypercube, which would allow even greater performance. 'To reiterate, the lookup table need only be computed once as long as the camera's height and inclination don't change. 


\section{SUMMARY}

The goal of this paper was to show how the spill detection and clean up algorithm currently implemented on the HERMIES.III mobile robot could be modified in order to utiliz: multiple performing robots with little or no modification of previously written codes. To that end, the following steps were outlined. First, sub-tasks that could be performed concurrently or consecutively and that required differing system performances were identified. Second, the sub-tasks were divided and a portion of them were allocated to a different robot, HERMIES-IIB. Third, the difficulties with a simple transferral of algorithms to the new robot were outlined, namely the inability of HERMIES-IIB cameras to assume the pose utilized by HERMIES-III during spill detection. Fourth, the method of inverse perspective mapping was explained as a solution to this problem, and initial experimental results were described. 


\section{REFERENCES}

1. University Program in Robotics for Advanced Reactors, U.S. Departinent of Energy, DOE/OR-884 Rev.2, February 1990.

2. C. Chen, C. R. Bidlack and M. M. Trivedi, A Robot Vision System for Automatic Spill Detection, Location and Clean-Up Verification, TR-ECE-8936, December 1989.

3. H. A. Mallot, E. Schulze and K. Storjohann, Neural Network Strategies for Robot Navigation, in: L. Personnaz and G. Dreyfus (Eds.) Neural Networks from Models to Applications, pp. 560-569, 1989.

4. R. O. Duda and P. E. Hart, Pattern Classfication and Scene Analysis, John Wiley \& Sons, New York, 1973.

5. R. C. Gonzalez, and P. Wintz, Digital Image Processing, Addison-Wesley Publishing Company, 1987.

6. R. Lenz, Linsenfehlerkorrigierte Eichung von Halbleiterkameras mit StandardObjektiven für hochgenaue 3D-Messungen in Echtzeit, Proc. Mustererkennung 1987, 9. DAGM Symposium, E. Paulus (Ed.), Springer Verlag, 1987. 
ORNL/TM-11661

\section{INTERNAL DISTRIBUTION}

1. B. R. Appleton

2. J. E. Baker

3. M. Beckerman

4. C. W. Glover

5. J. P. Jones

S-10. H. E. Knee

11. G. E. Liepins

12. F. C. Maienschein

13-17. R. C. Mann

18-22. E. M. Oblow

23. F. G. Pin

24. D. B. Reister

25-29. F. J. Sweeney

30. M. A. Unseren
31. J. J. Dorning (consultant)

32. R. M. Haralick (consultant)

33. J. E. Leiss (consultant)

34. M. F. Wheeler (consultant)

35. N. Moray (consultant)

36. EPMD Reports Office

37-38. Laboratory Records Department

39. Laboratory Records, ORNL-RC

40. Document Reference Section

41. Central Research Library

42. ORNL Patent Section

\section{EXTERNAL DISTRIBUTION}

43. P. Ailen, Department of Computer Science, 450 Computer Science Columbia University, New York, New York 10027

44. H. Alter, MS-542, Division of Advanced Technology Development, 19901 Germantown Road, U.S. Department of Energy, Washington, DC 20545

45. W. Book, Department of Mechanical Engineering, J. S. Coon Building, Room 306, Cherry Street, Georgia Institute of Technology, Atlanta, GA 30332

46. S. Dubowsky, Building 3 - Room 469A, Massachusetts Institute of Technology, 77 Massachusetts Avenue, Cambridge, MA 02139

47. A. Kak, Department of Electrical Engineering, Purdue University, Northwestern Avenue - Engineering Mall, Lafayette, IN 47907

48. O. Manley, DOE Headquarters - ER-15, Division of Engineering and Geosciences, Office of Basic Energy Sciences, Germantown, MD 20545

49. W. von Seelen, Ruhr Universität Bochum, Institut für Neuroinformatik, Universitätsstr 150, 4630 Bochum-1, West Germany

50. K. Storjohann, Ruhr Universitä́s Bochum, Institut für Neuroinformatik, Universitätsstr 150, 4630 Bochum-1, West Germary

51. W. Snyder, Center for Communications and Signal Process...g, North Carolina State University - Box 7914, Raleigh, NC 27695-7914

52. Office of Assistant Manager, Energy Research and Development, Oak Ridge Operations Office, US/DOE, P.O. Box 2001, Oak Ridge, TN 37831

53-54. Office of Scientific and Technical Information, US/DOE, Oak Ridge, TN 37831

55. E. L. Saltzen, 3301 Fosberg 121, Turlock, CA 95380 

